\title{
The Cost of Integrating a Physical Activity Counselor in the Primary Health Care Team
}

\author{
William E. Hogg, MD, MSc, Xue Zhao, PhD, Douglas Angus, MSc, \\ Michelle Fortier, PhD, Jianwei Zhong, PhD, Tracey O'Sullivan, PhD, \\ Ronald J. Sigal, MD, and Chris Blanchard, PhD
}

Objective: This article assesses direct costs of integrating a physical activity counselor (PAC) into primary health care teams to improve physical activity levels of inactive patients.

Methods: A monthly cost analysis was conducted using data from 120 inactive patients, aged 18 to 69 years, who were recruited from a community-based family medicine practice. Relevant cost items for the intensive counseling group included (1) office expenses; (2) equipment purchases; (3) operating costs; (4) costs of training the PAC; and (5) labor costs. Physical and human capital were amortized over a 5 -year horizon at a discount rate of $5 \%$.

Results: Integrating a PAC into the primary health care team incurred an estimated one-time cost of CA\$91.43 per participant per month. Results were very sensitive to the number of patients counseled.

Conclusions: The costs associated with the intervention are lower than many other intervention studies attempting to improve population physical activity levels. Demonstrating this competitive cost base should encourage additional research to assess the effectiveness of integrating a PAC into primary health care teams to promote active living among patients who do not meet recommended physical activity levels. (J Am Board Fam Med 2012;25:250-252.)

Keywords: Cost Analysis, Counseling, Health Care Team, Motor Activity, Primary Health Care

Consistent with the World Health Organization's recognition of physical inactivity as one of the leading risk factors for morbidity and mortality, ${ }^{1,2}$ re-

This article was externally peer reviewed.

Submitted 1 May 2011; revised 28 November 2011; accepted 5 December 2011.

From the Department of Family Medicine (WEH), the Institute of Population Health (WEH, DA), and the School of Psychology (MF, TO), University of Ottawa, Ottawa, Ontario, Canada; C.T. Lamont Primary Health Care Research Centre, Élisabeth Bruyère Research Institute, Ottawa, Ontario, Canada (WEH, JZ); Department of Economics, Carleton University, Ottawa, Ontario, Canada (XZ); Departments of Medicine, Cardiac Sciences, and Community Health Sciences, University of Calgary, Calgary, Alberta, Canada (RJS); and Department of Medicine, Dalhousie University, Halifax, Nova Scotia, Canada (CB).

Funding: Funding for this research was provided by the Ontario Ministry of Health and Long-Term Care Primary Health Care Transition Fund.

Conflict of interest: none declared.

Disclaimer: The views expressed in this article are the views of the authors and do not necessarily reflect those of the Ontario Ministry of Health and Long-Term Care.

Corresponding author: William Hogg, MD, MSc, Department of Family Medicine, University of Ottawa, 43 Bruyère Street, Ottawa, Ontario, K1N 5C8, Canada (E-mail: whogg@uottawa.ca). search shows that physical activity has many benefits and can prevent and improve chronic disease. $^{3-8}$ One potential and promising way of increasing physical activity may be to incorporate physical activity counselors (PACs) into primary care settings.

Physical activity (PA) promotion programs have received little attention in economic feasibility analyses, especially in Canadian settings. Current literature revealed only a few cost-consequence analyses, cost-effectiveness analyses, or cost analyses evaluating PA promotion projects. ${ }^{1,9}$ Nevertheless, Katzmarzyk et $\mathrm{al}^{10}$ have estimated that for every 10\% increase in PA participation in Canada, there is a cost offset of $\$ 150$ million annually in direct health care expenses. In consequence, the economic evaluation of PA promotion programs has strong policy implications for Canada, which has a Medicare system through which medically necessary physician services are paid through a taxsupported public system. Recent efforts to reform primary care services have featured a transition to teams where the government pays the salaries of 
allied health professionals from a wide variety of disciplines to work with family physicians in practices usually owned by the physicians.

The purpose of this study was to conduct a pilot study assessing the monthly program costs of integrating a PAC into a primary care team. The setting for this pilot project was a single communitybased primary care practice in Ottawa, Ontario, serving approximately 10,000 predominantly Francophone patients, $75 \%$ of whom $(n=7,500)$ are seen annually. Patients recruited for the project were 18 to 69 years of age; reported they do not meet the guideline of at least 150 minutes per week of $\mathrm{PA}$; indicated during recruitment that they were somewhat motivated to change; and were free of unstable or uncontrolled medical conditions. Pregnant women were excluded.

The project was a 2 -arm stratified, randomized controlled trial completed in 2005. In one arm, patients received brief PA counseling from their physician or nurse practitioner. In the second arm, patients received brief PA counseling from their provider as well as intensive counseling from a PAC. The PAC in our project held an undergraduate university degree in exercise science as well as a certification from the Canadian Society for Exercise Physiology. Ethics approval for the project was granted by the University of Ottawa, Montfort Hospital, and Ottawa Hospital Research Institute ethics boards.

There were 61 subjects randomized into the intervention group to receive the counseling from the PAC, and 59 were provided brief counseling only. The methods are published elsewhere in detail, including a study flow diagram. ${ }^{11}$

We proposed a cost study only because it is important to know the cost to determine if this approach is feasible. The relevant cost items for the intervention were classified under 5 headings: (1) office expenses; (2) equipment purchases; (3) operating costs; (4) costs of training the PAC; and (5) labor costs. Before the onset of the trial, the PAC received 2 months of training to develop an autonomic, supportive style and to learn and practice motivational interviewing techniques. ${ }^{11}$

In our cost analysis, we assumed the discount rate to be $5 \%$, and the costs were amortized over 5 years. By varying the discount rate, we estimated the amortized costs for both physical capital (equipment purchases) and human capital (PAC training). Project costs are detailed in Table 1.

Our results are consistent with some of the reports from the literature based on nominal price comparison. ${ }^{12-15}$ At the end of the 3-month inten-

Table 1. Incremental Cost Components At the End of the 3-Month Intervention

\begin{tabular}{lrr}
\hline Cost components & $\begin{array}{c}\text { Amount At End of } \\
\text { Intervention, CAS }(\mathrm{n}=61)\end{array}$ & $\begin{array}{c}\text { Percentage of } \\
\text { the Total Direct Costs }\end{array}$ \\
\hline Office & 1200.00 & 7.2 \\
Equipment* & 671.72 & 4.0 \\
$\quad$ Computers & 455.61 & 2.7 \\
Printer & 150.84 & 0.9 \\
Furniture & 64.67 & 0.4 \\
Operating costs & 4149.92 & 24.8 \\
Supervision & 750.00 & 4.5 \\
Miscellaneous & 1652.17 & 9.9 \\
Office supplies & 200.00 & 1.2 \\
Telephone/Internet & 1547.75 & 9.3 \\
PAC training* & 666.26 & 4.0 \\
Experts & 268.52 & 1.6 \\
Orientations & 161.68 & 1.0 \\
Professional development & 236.06 & 1.4 \\
Labor costs & 12553.98 & 60.0 \\
Total direct cost & 16731.08 & 100.0 \\
Total direct cost per participant & 274.28 & \\
Total direct cost per participant per month & 91.43 & \\
\hline
\end{tabular}

*Amortized over a 5-year horizon.

PAC, physical activity counselor. 
sive counseling intervention, the direct health cost per participant was $\$ 274.28$ and the average cost per month was \$91.43. Average cost per patient dropped sharply as the number of patients counseled increased, reflecting an approximation of unused PAC capacity. We estimated that the counselor could counsel up to 90 patients during the same intervention. The cost of integrating a PAC into the primary health care system was relatively inexpensive compared with other PA promotion projects reported in the literature, ${ }^{12-15}$ so it is reasonable to proceed now with studies to determine if co-locating a PAC in the primary care setting is effective in increasing the activity of inactive members of the practice.

\section{References}

1. Blair SN, Applegate WB, Dunn AL, et al. Activity Counseling Trial (ACT): rationale, design, and methods. Med Sc Sports Exer 1998;30:1097-106.

2. World Health Organization. The Heidelberg guidelines for promoting physical activity among older persons. Geneva, Switzerland: WHO; 1996.

3. Bouchard C, Shephard RJ, Stephens T. Physical activity, fitness, and health: the model and key concepts. In: Physical activity, fitness and health: international proceedings and consensus statement. Champaign, IL: Human Kinetics; 1994:77-88.

4. Mao Y, Pan S, Wen SW, Johnson KC. Physical inactivity, energy intake, obesity and the risk of rectal cancer in Canada. Int J Cancer 2003;105:831-7.

5. Myers JM, Prakash M, Froelicher V, Do D, Partington S, Atwood JE. Exercise capacity and mortality among men referred for exercise testing. N Engl J Med 2002;346:793-801.
6. Tanasescu M, Leitzmann MF, Rimm EB, Hu FB. Physical activity in relation to cardiovascular disease and total mortality among men with type 2 diabetes. Circulation 2003;107:2435-9.

7. Knowler WC, Barrett-Connor E, Fowler SE, et al. Reduction in the incidence of type 2 diabetes with lifestyle intervention or metformin. $\mathrm{N}$ Engl J Med 2002;246:393-403.

8. Diabetes Prevention Program (DPP) Research Group. The Diabetes Prevention Program (DPP): description of lifestyle intervention. Diabetes Care 2002;25:2165-71.

9. Petrella RJ, Lattanzio CN. Does counseling help patients get active? Systematic review of the literature. Can Fam Physician 2002;48:72-80.

10. Katzmarzyk PT, Gledhill N, Shephard RJ. The economic burden of physical inactivity in Canada. CMAJ 2000;163:1435-40.

11. Fortier MS, Hogg W, O'Sullivan TL, et al. The physical activity counselling (PAC) randomized controlled trial: rationale, methods, and interventions. Appl Physiol Nutr Metab 2007;32:1170-85.

12. Stevens $W$, Hillsdon M, Thorogood M, McArdle D. Cost-effectiveness of a primary care based physical activity intervention in 45-74 year old men and women: a randomised controlled trial. Br J Sports Med 1998;32:236-41.

13. Dzator JA, Hendrie D, Burke V, et al. A randomized trial of interactive group sessions achieved greater improvements in nutrition and physical activity at a tiny increase in cost. J Clin Epidemiol 2004;57:610-9.

14. Sevick MA, Dunn AL, Morrow MS, Marcus BH, Chen GJ, Blair SN. Cost-effectiveness of lifestyle and structured exercise interventions in sedentary adults: results of project ACTIVE. Am J Prev Med 2000;19:1-8.

15. Yanagawa TL, Wang G, Pratt M, Roux L. The cost of physical activity promotion interventions. Med Sci Sports Exerc 2004;36(Suppl):213. 